\title{
PERAN KETELADANAN ORANG TUA DALAM MEMBENTUK AKHLAK REMAJA BERPRESTASI (Studi Kasus Siswa SMP Muhammadiyah 1 Sentolo Kulon Progo)
}

\author{
Ita Rusna Dewi \\ Program Pasca Sarjana Magister Studi Islam \\ Universitas Muhammadiyah Yogyakarta \\ E-mail: itarusna@gmail.com
}

\begin{abstract}
Abstrak
Penelitian ini bertujuan untuk ; 1 . Mengetahui pemahaman orang tua dalam mendidik remaja berprestasi SMP Muhammadiyah 1 Sentolo, Kulon Progo; 2. Mengetahui peran keteladanan orang tua dalam membentuk akhlak remaja berprestasi SMP Muhammadiyah 1 Sentolo. Jenis penelitian yang digunakan adalah deskriptif kualitatif. Lokasi yang peneliti pilih adalah SMP Muhammadiyah 1 Sentolo Kabupaten Kulon Progo. Dalam tekhnik pengumpulan data penulis menggunakan wawancara mendalam dan dokumentasi. Berdasarkan hasil penelitian yang penulis lakukan dalam penelitian ini, dapat disimpulkan ; 1 . Rasa tanggung jawab yang besar pada orang tua dalam tumbuh kembang remaja menjadikan kekuatan untuk selalu memberikan pengasuhan dan pendidikan yang baik bagi anak-anaknya. 2. Keteladanan para orang tua dalam membentuk akhlak remaja berprestasi meliputi keteladanan dalam intelektual, keteladanan dalam emosional dan keteladanan dalam spiritual. Dengan prinsip selalu berusaha memberikan yang terbaik untuk anak-anaknya agar mampu menikmati kehidupan yang lebih baik.
\end{abstract}

Kata kunci: keteladanan orang tua, prestasi dan akhlak remaja

\begin{abstract}
This research aims to ; 1. Knowing the parent's understanding in educating outstanding teenagers SMP Muhammadiyah 1 Sentolo, Kulon Progo; 2. Knowing the role of exemplary parents in shaping the morale of outstanding teenagers SMP Muhammadiyah 1 Sentolo. The type of research used is descriptive qualitative. The location that the researcher chose was SMP Muhammadiyah 1 Sentolo Kulon Progo Regency. In data collection techniques the author uses in-depth interviews and documentation. Based on the results of research that the authors do in this study, it can be concluded; 1 . A great sense of responsibility for parents in growing teenagers makes the power to always provide good care and education for their children. 2. Exemplary parents in shaping the morals of outstanding teenagers include exemplary in intellectual, exemplary in emotional and exemplary in the spiritual. With the principle of always trying to give the best for their children to be able to enjoy a better life.
\end{abstract}

Keywords: exemplary parent, achievement and morals adolescent

\section{Info Artikel}

Diterima Maret 2018, disetujui April 2018, diterbitkan Juni 2018 


\section{PENDAHULUAN}

Seorang anak adalah imitasi dari orang tuanya. Dengan "melihat" anak akan menyimpan hasil pengamatannya tersebut kemudian akan menjadi bahan acuan untuk melakukan hal yang sama. Awal mula pendidikan yang diterima anak berasal dari kedua orang tuanya. Orang tua yang mampu menampilkan sikap baik di depan anaknya maka akan menjadikan bekal bagi masa depan anak kelak. Begitu pula dalam hal buruk anak akan cepat menyerap kemudian menirunya.

Pendidikan anak khususnya remaja pada saat ini berbeda dengan zaman dulu. Di zaman dulu anak cukup diberikan nasihat oleh orang tua sudah akan nurut. Sedangkan saat ini apabila orang tua memberikan nasihat harus disiapkan berbagai alasan untuk menjawab pertanyaan tentang rasa penasaran atau sekedar ingin membangkang kepada orang tua. Kodrat seorang anak dari dulu sebenarnya sama yakni menjadi bagian dari sebuah keluarga yang dipimpin oleh orang tua, akan tetapi zaman yang sudah berbeda. Apabila dahulu yang terlihat adalah orang tua yang hanya bekerja untuk mencukupi segala kebutuhan anak, sedangkan zaman sekarang orang tua memiliki kesibukan yang beragam.

Dewasa ini pendidikan mengalami beragam tantangan, moral dianggap telah berantakan. Mulai dari teman sebaya yang memiliki pengaruh kuat hingga gadget yang setiap hari dapat memberikan informasi baik positif maupun negative. Anak yang belum memahami tentang baik buruk informasi tersebut maka mereka akan mengambil tanpa berfikir panjang. Namun apabila seorang anak telah dibekali pengetahuan tentang baik buruknya informasi maka mereka akan mampu memilih dan memilah. Mereka akan memiliki rem sebagai pengontrol diri agar tidak terjerumus ke hal-hal yang negative.

\section{PEMBAHASAN}

\section{Pemahaman Orang Tua Siswa Berprestasi SMP Muhammadiyah 1 Sentolo dalam Mendidik Anak}

Mendidik anak adalah amanah dari Allah, untuk itu anak harus dididik dengan keadaan yang sesuai dengan zamannya, bukan seperti di zaman dulu. Sehingga orang tua harus mempersiapkan bekal pada anak untuk menyongsong zaman yang semakin modern. Misalnya mempersiapkan intelektual, emosional dan spiritual anak. Peneliti akan mengangkat bentuk keteladanan orang tua siswa berprestasi SMP Muhammadiyah 1 Sentolo dalam ketiga hal tersebut :

1. Keteladanan Intelektual

Yang harus dilakukan orang tua dalam mempersiapkan intelektual anak adalah :

a. Pendampingan, dalam hal ini orang tua melakukan pendampingan terkait kesulitan-kesulitan yang dihadapi oleh anak utamanya kesulitan dalam belajar. Misalnya saat jam belajar anak 
ditemani, dibantu memahami pelajaran dari sekolah dan lain sebagainya. Dari beberapa informan orang tua siswa berprestasi SMP Muhammadiyah 1 Sentolo melakukan pendampingan dalam proses belajar anak belum secara sempurna. Alasan yang mereka sampaikan karena anak-anak mereka sudah cukup besar sehingga mereka dapat melakukan belajar secara mandiri. Selain itu, anak terkadang merasa keberatan untuk didampingi oleh orang tuanya, mereka lebih senang belajar dengan kakak atau teman sebaya yang mereka anggap lebih paham dibanding orang tuanya.

b. Perintah, dalam hal ini orang tua memberikan saran dan melakukan komunikasi tentang materi yang diterima oleh anak. Misalnya anak diberikan buku-buku penunjang untuk dibaca terkait keilmuan yang ada di sekolah atau anak dimasukkan bimbingan belajar untuk mendapat tambahan pelajaran selain dari sekolah. Dalam hal perintah, para informan orang tua siswa berprestasi SMP Muhammadiyah 1 Sentolo sudah melaksanakan dengan baik, seperti menyuruh untuk membiasakan membaca, tetapi memang para orang tua tidak memasukkan mereka di bimbingan belajar Karena keterbatasan ekonomi. Orang tua juga tidak membelikan buku untuk anak mereka tetapi anak-anak disuruh meminjam di perpustakaan mana saja.

c. Pembatasan, orang tua memberikan rambu-rambu kepada anak untuk dipatuhi dan tidak boleh dilanggar. Misalnya dalam hal pergaulan anak tidak dibolehkan main di jam belajar, bermain terlalu lama dan sebagainya. Dalam hal pembatasan pergaulan maupun aktifitas, orang tua siswa berprestasi SMP Muhammadiyah 1 Sentolo telah melaksanakan dengan baik, meskipun ada beberapa anak yang terkadang membangkang atau melanggar aturan pembatasan tersebut. Siswa berprestasi SMP Muhammadiyah 1 Sentolo rata-rata berusia 15 tahun sehingga pergaulan mereka sudah mulai melebar. Dalam pembatasan ini anak-anak cukup menyadari karena memang mereka punya keinginan untuk memiliki nilai baik sehingga mampu mengelola waktu dengan baik. Waktunya belajar akan mereka gunakan untuk belajar dan waktu untuk bermain akan 
mereka gunakan untuk bermain.

2. Keteladanan Emosional

Orang tua diharuskan memberikan pembekalan emosional terhadap anaknya agar anak mampu mandiri dan menghadapi berbagai masalah kedepannya. Salovey dan Gardner dalam buku Daniel Goleman meyatakan bahwa lima ciri khusus kecerdasan emosional antara lain :

a. Mengenali emosi diri yakni kesadaran diri untuk mengenali perasaan sewaktu perasaan itu terjadi, hal ini merupakan dasar kecerdasan emosional.

b. Mengelola emosi

c. Memotivasi diri sendiri

d. Mengenali emosi orang lain (empati)

e. Membina hubungan

Orang tua yang hendak memberikan bekal pendidikan kepada anak haruslah menguasai tentang keilmuan tersebut. Untuk memberikan bekal keteladanan emosional kepada anak hendaknya orang tua memahami tentang bidang emosional tersebut. Para informan orang tua siswa berprestasi SMP Muhammadiyah 1 Sentolo telah dapat dikatakan mampu memberikan contoh dalam hal emosional karena mereka telah mampu mengenali emosi terbukti dari jawaban yang disampaikan saat ditanya tentang sudah memberikan contoh yang baik untuk anak mereka sepakat telah memberikan contoh yang baik, bahkan mereka menyadari bahwa memberikan yang terbaik untuk anak adalah kewajiban orang tua.

Dalam mengelola emosi, para informan sudah mampu dalam mengelolanya terlebih mengelola emosi saat menghadapi anak. Hal ini sesuai dengan jawaban yang disampaikan saat ditanya bagaimana sikap orang tua bila melihat anak tidak sesuai dengan harapan, mereka menjawab jengkel akan tetapi kemudian menyampaikan mau bagaimanapun tetaplah anak sehingga kasih sayang mereka lebih banyak dibanding kemarahan ataupun kejengkelan dalam hatinya.

Dalam hal memotivasi diri sendiri, para informan sudah sangat terbiasa. Hal ini terbukti dari perilaku yang mereka lakukan dalam bekerja setiap harinya. Para informan rata-rata bekerja 7 sampai 8 jam setiap hari, itu dilakukan karena rasa tanggung jawabnya terhadap keluarga utamanya terhadap anak. Saat ditanya motif dari mereka bekerja semua dilakukan untuk keluarga agar dapat hidup dengan layak.

Dalam mengenali emosi orang lain (empati) yang informan lakukan adalah dalam hidup berdampingan dengan masyarakat. Para informan kebanyakan tinggal dalam suatu kampung yang berdekatan satu dengan yang 
lainnya. Mereka sering bertemu dan melakukan kegiatan bersamasama di lingkungan masyarakat seperti misalnya kerja bakti, arisan, saling menjenguk apabila salah satunya sakit juga melakukan siskamling di malam hari. Kebiasaan-kebiasaan tersebut membuktikan bahwa mereka mampu mengenali emosi orang lain, memiliki empati terhadap sekitar. Hal ini sekaligus menjawab tentang unsur membina hubungan dalam pendidikan emosional.

3. Keteladanan Spiritual

Dalam keteladanan spiritual para orang tua diharuskan untuk melakukan beberapa tindakan, antara lain :

a. Pendampingan, orang tua harus melakukan pendampingan saat anak sedang memahami aqidah atau melakukan ibadah. Orang tua memberikan contoh yang benar dalam memahami aqidah dan melaksanakan ibadah. Misalnya pemikiran-pemikiran tentang hal-hal ghaib anak tidak boleh keliru sehingga mereka beranggapan bahwa kehidupan hanya di dunia saja. Juga tentang tata cara ibadah yang benar orang tua harus selalu meluruskannya. Dalam pendampingan keteladanan spiritual, orang tua siswa berprestasi SMP Muhammadiyah 1 Sentolo telah melakukannya dengan baik. Terbukti dengan kebiasaan shalat dan pengajian-pengajian yang telah dilakukan dan diikuti, sehingga ketika orang tua mendapati anak mengajukan pertanyaan yang mendalam orang tua akan menanyakannya pada ustadz atau kyai yang mengisi pengajian tersebut. sehingga dapat diartikan fasilitas pendampingan keteladanan spiritual anak terpenuhi dengan baik.

b. Larangan, orang tua memberikan larangan-larangan yang dimungkinkan akan membahayakan diri anak. Dalam hal spiritual larangan dari orang tua bersifat jangka panjang hingga ke akhirat. Sehingga larangan yang diberikan orang tua adalah yang dilarang oleh agama. Seperti larangan minum khamr, larangan mendekati zina padahal di usia remaja adalah saat-saat rasa pencarian jati diri ingin dianggap hebat. Dalam pemberlakuan larangan ini sedikit mengalami kendala karena tidak jarang anak akan membangkang dan memilih kabur dari rumah. Dalam keteladanan spiritual yang menetapkan larangan, para informan orang tua siswa berprestasi SMP Muhammadiyah 1 Sentolo 
telah melakukan hal tersebut. Mereka telah memberlakukan aturan larangan terhadap anaknya antara lain melarang untuk pacaran karena hal tersebut mendekati zina dan merusak konsentrasi belajar. Melarang anak merokok karena dapat keterusan untuk berani minum khamr atau menggunakan obat terlarang. Sehingga dapat dikatakan orang tua menerapkan larangan dengan benar sesuai ajaran Islam.

\section{Peran Keteladanan Orang Tua dalam Membentuk Akhlak Remaja Berprestasi SMP Muhammadiyah 1 Sentolo}

Siswa SMP Muhammadiyah 1 Sentolo kelas 9 yang masuk dalam peringkat 10 besar menggambarkan akhlak yang dimiliki mereka masih belum stabil. Ini terlihat dari cara mereka menyampaikan jawaban saat diwawancara. Satu sama lain memiliki beberapa persamaan dalam jawaban yang intinya memang masih ikutikutan. Dari para informan menyatakan bahwa diri mereka paham tentang akhlak baik, sesuai dengan jawaban berikut :

"ya, saya paham yang dimaksud akhlak baik itu ya berhati mulia, mempunyai sifat yang baik terhadap orang lain terutama pada orang yang lebih tua dari kita harus menghormati”.
Maksud inti dari jawaban tersebut, akhlak adalah menghormati orang tua dan baik terhadap sesama, yakni sopan santun, bertutur kata baik dan suka membantu. Jawaban ini sudah dapat dianggap memiliki pemahaman yang baik tentang akhlak. Yang lain menyampaikan :

"paham... Ya berbakti kepada orang tua, bersikap adil pada orang tua misalnya kalau punya makanan ya dibagi rata, semua dirasani".

Dari jawaban di atas mengidentifikasi bahwa kebiasaan dia berbakti terhadap orang tua, mengikuti apa saja yang menjadi perintah orang tua. Terlebih dia menyampaikan tentang makanan yang dimiliki dibagi rata itu artinya dari hal-hal sederhana dia telah menunjukkan baktinya kepada orang tua. Jawaban tersebut sesuai dengan keadaan yang dialaminya karena memang dia hingga saat ini mengaku tinggal bersama mbahnya yang sudah tua untuk menemani dan mengurusinya. Ada juga yang menyampaikan :

"paham... akhlak yang baik itu ya pikiran atau akal yang baik. Maksudnya berfikir yang baikbaik saja, tidak berfikir anehaneh".

Jawaban tersebut menunjukkan bahwa dia menganggap bahwa pikiran itulah yang akan membawa seseorang kepada perbuatan. Bila pikiran baik maka akan mengeluarkan sikap-sikap yang baik, akan tetapi bila berfikir yang kurang baik atau malah buruk 
maka dapat menimbulkan berbagai sifat atau sikap yang buruk pula.

Selanjutnya dari semua informan sependapat bahwa mereka mempunyai sesuatu yang dinamakan akhlak baik tersebut, dengan berbagai contoh yang beragam. Jawaban dari para informan antara lain :

"ya.. ada. Contohnya ya mengajak teman untuk shalat, untuk berbicara yang baik, sopan dan enak didengar".

Yang lain menyampaikan : "punya... shalat 5 waktu, berbuat baik, berbakti pada orang tua, membantu orang tua (bersih-bersih rumah) tapi ya kadang-kadang sich...."

"Punya... menolong teman, infaq di sekolah, mengerjakan tugas sekolah, berbakti kepada orang tua"

Dari jawaban-jawaban di atas terlihat bahwa mereka paham dan telah melakukan tindakan yang sesuai dengan akhlak. Dengan mengajak kepada kebaikan, berbakti kepada orang tua, infaq sudah menunjukkan memiliki akhlak baik yang dimaksud peneliti.

Saat waktu luang, para informan juga menyampaikan bahwa mereka melakukan hal yang hampir sama yakni bermain HP atau nonton TV, seperti disampaikan berikut : 'main dengan temen-temen, atau tidur atau bermain HP'.
Jawaban lain menyampaikan bahwa saat waktu luang diginakan untuk :

"main HP dan nonton TV, atau main sama temen-temen di lingkungan rumah. Tapi kalo malam biasanya saya menghabiskan waktu untuk membaca Al Qur'an".

Jawaban yang berbeda disampaikan salah satu informan yang tinggal tidak bersama orang tuanya, akan tetapi di panti asuhan di Sentolo. Tentu saja kehidupan di panti berbeda dengan teman yang lain yang di rumah bersama kedua orang tua. Di panti telah terjadwal kegiatan-kegiatan bermanfaat dalam kesehariannya, jarang ada waktu luang. Namun demikian karena dia menyampaikan waktu luangnya digunakan sebagai berikut :

"bercerita dengan temen, membaca kadang membaca buku cerita atau Al Qur'an, atau tidur atau bermain".

Selanjutnya dengan pertanyaan mengenai keinginan yang belum tercapai yang peneliti maksudkan adalah yang kaitannya dengan perbuatan baik, beberapa informan menyampaikan bahwa mereka ingin focus belajar supaya dapat nilai baik. Mereka sadar sudah di kelas 9 sehingga waktu untuk di SMP tidak lama dan harus mempersiapkan diri mencari jenjang sekolah yang lebih tinggi. Jawaban dari informan antara lain : 
"ingin mendapat prestasi baik, bisa punya nilai baik".

Hal serupa disampaikan oleh informan lain :

"saya ingin selalu jalan-jalan, saya juga ingin masuk ke sekolah pilihan".

Sedangkan salah satu informan menyampaikan :

"saya ingin bisa shalat 5 waktu dengan tepat, karena selama ini saya masih kadang bolongbolong, kadang sampai berlarutlarut di akhir waktu baru ingat shalat".

Selanjutnya dari pertanyaan peneliti yang menanyakan tentang sikap saat berada pada posisi yang disalahkan, para informan menyampaikan rasa kesal dengan berbagai reaksi yang berbeda. 5 informan menyatakan diri untuk membantah dan tidak terima, 2 informan menjawab hanya menangis dan merasa bersalah tapi tidak punya kuasa untuk membantah, dan 3 orang menyampaikan keteguhan hatinya dengan diam dan mengalah untuk menghindari perdebatan. Yang menyatakan untuk membantah antara lain : 'Saya tidak terima dan berusaha membantahnya sebisa mungkin, tapi tetap menjalankan perilaku yang baik'. Sedangkan 2 informan yang menyatakan menangis menyampaikan:

"Sedih, curhat sama temen lalu kadang nangis, karena jadi merasa bersalah kalau terus disalahkan".
Informan yang lain menyatakan keteguhan dan kesabarannya dengan menyampaikan :

"Saya akan menerima dengan teguh hati'. 'Saya akan meminta maaf".

Selanjutnya saat ditanyakan tentang reaksi yang akan terjadi saat mendengar orang tua sakit, semuanya menyampaikan kesedihannya dan berjanji untuk merawat orang tua yang sedang sakit tersebut. sedangkan apabila orang lain yang sakit mereka juga sepakat akan menjenguk teman atau saudara yang sedang sakit.

Selanjutnya peneliti menanyakan pentingnya sebuah peraturan, mereka sepakat menyampaikan pentingnya aturan ditegakkan sebagai bentuk kedisiplinan dan ketertiban. Selanjutnya dengan pertanyaan perilaku yang dilakukan apabila tidak sengaja melanggar aturan, para informanya menjawab instruspeksi diri.

Dari jawaban para informan siswa SMP Muhammadiyah 1 Sentolo yang berprestasi dapat dikatakan bahwa mereka paham tentang akhlak, memiliki akhlak baik dan mampu melaksanakan dalam kehidupan sehari-hari. Akhlak yang mereka miliki masuk dalam kategori sedang, tidak terlalu baik juga tidak terlalu buruk. Untuk pengkategoriaanya penulis sampaikan di pembahasan. 


\section{KESIMPULAN DAN SARAN}

\section{Kesimpulan}

1. Pemahaman orang tua siswa berprestasi SMP Muhammadiyah 1 Sentolo mengenai perannya sebagai orang tua telah baik. Mereka telah mampu menjadi contoh dan pendidik bagi anaknya. Dalam menjadi contoh meliputi aktifitas keseharian yakni perilaku yang dilakukan sehari-hari dari bangun tidur hingga tidur di malam hari. Selanjutnya sebagai pendidik di berbagai bidang meliputi intelektual yang didalamnya mengajarkan tentang materi yang ada kaitannya dengan keilmuankeilmuan atau materi di sekolah yang berhubungan dengan akademik. Juga bidang emosional yang meliputi perilaku saat berhubungan dengan orang lain serta penempatan diri saat bersosialisasi di lingkungan hingga memahamkan anak saat mengalami berbagai masalah pada diri. Dan bidang spiritual yang mengajarkan untuk senantiasa menjaga hubungan baik dengan Tuhan Yang Maha Esa meliputi pengenalan aqidah, pelaksanaan ibadah, tata cara bermuamalah dan lain sebagainya.

2. Peran keteladanan orang tua dalam membentuk akhlak siswa berprestasi di SMP Muhammadiyah 1 Sentolo meliputi sebagai pondasi dalam pembentukan diri anak, baik dalam hal intelektual, emosional maupun spiritual. Dalam hal intelektual anak diantarkan menuju pencapaian prestasi yang baik dalam hal akademik maupun non akademik. Dalam hal emosional dan spiritual anak dilatih untuk mengelola emosi diri sesuai ajaran agama yang benar sehingga mampu menghasilkan akhlak terpuji. Selain itu keteladanan orang tua mampu menjadi sarana mendekatkan diri kepada Allah dan pembentukan keluarga qurrata a'yun.

\section{Saran}

1. Kepada para orang tua siswa utamanya di SMP Muhammadiyah 1 Sentolo hendaklah memahami secara keseluruhan perannya sebagai orang tua. Dengan demikian akan mampu meluangkan waktu secara khusus untuk memantau perkembangan anak remajanya yang berada di usia rawan penyimpangan.

2. Kepada segenap guru di sekolah utamanya di SMP Muhammadiyah 1 Sentolo disarankan untuk selalu menjalin komunikasi yang baik kepada anak didik dan orang tua/wali. Karena ketika komunikasi tersebut berjalan baik maka kesempatan siswa untuk melakukan tindakan melenceng kecil. 
3. Kepada para siswa SMP Muhammadiyah 1 Sentolo hendaklah saling mengingatkan dalam hal kebaikan. Ketika para siswa mampu saling mengingatkan maka terjalinlah hubungan yang baik antar remaja.

\section{DAFTAR PUSTAKA}

Ahmadi, Abu \& Munawar Sholeh. Psikologi Perkembangan

Al-Ausyan, Majid Sa'ud. 2015. Adab \& Akhlak Islami Berdasarkan Al Qur'an dan Sunnah. Jakarta : Darul Haq

Al Qur'an Digital. Versi 2.1. 2004.

Asmawati Bte Suhid, Pemantapan Komponen Akhlak dalam Pendidikan Islam Menghadapi Era Globalisasi

Atmaja Prawira, Purwa. 2016. Psikologi Kepribadian Dengan Perspektif Baru. Jogjakarta : ArRuzz Media

Baharuddin, M.Ag. Prof. Dr.. 2007. Paradigma Psikologi Islami. Yogyakarta : Pustaka Pelajar

Brook, Judith S. 2006. The Relationship of Personality and Behavioral Development from Adolescence to Young Adulthood and Subsequent Parenting Behavior. Jurnal Psychological Reports. Stony Brook University, State University of New York

Budiyono, Yuni Harmawati. 2017. Penguatan Pendidikan Karakter melalui Nilai-nilai Keteladanan Guru dan Orang Tua pada Siswa Sekolah Dasar. Prosiding Seminar Nasional PPKn III

Cervone, Daniel \& Laurence A Pervin. 2008. Kepribadian : Teori dan Penelitian. Jakarta : Salemba Humanika

Desmita. $2015 . \quad$ Psikologi perkembangan. Bandung : PT Remaja Rosdakarya

Efendi, Dr. Mohammad. 2006. Pengantar Psikopedagogik Anak Berkelainan. Jakarta : PT Bumi Aksara

Ghazali, Imam. 2015. Ringkasan Ihya' Ulumuddin. Jakarta : PT Sahara

Goleman, Daniel. 1999. Emosional Intelligensi. Jakarta : PT Gramedia Pustaka Utama

H.A. Mustofa. 1997. Akhlak Tasawuf. Bandung : CV Pustaka Setia

Ilyas, Prof. Dr. H. Yunahar. 2015. Kuliah Akhlak. Yogyakarta : LPPI

Istinganah, Ifa. 2015. Pengaruh Keteladanan Guru Aqidah Akhlak dan Keteladanan Orang Tua terhadap Nilai-nila Akhlakul Karimah Siswa di MTsN se Kabupaten Blitar. Tesis PAI IAIN Tulungagung

Jalaludin. 2005. Psikologi Agama. Jakarta : Raja Grafindo Persada 
Kementrian Agama RI. 1998. Al Qur'an dan terjemahnya

Mansur. 2005. Pendidikan Anak Usia Dini Dalam Islam. Yogyakarta : Pustaka Pelajar

Marimba, Ahmad D. 1989. Pengantar Filsafat Pendidikan Islam. Bandung : Al-Ma'arif

Mayasari, Feri. Fakultas Psikologi Universitas Semarang

Musthofa Al-Maraghi, Ahmad. 1987. Terjemah Tafsir Al Maraghi Juz 9. Semarang : Thoha Putra

Najati, M Ustman. 1995. Al Qur'an dan Ilmu Jiwa. Bandung : Pustaka

Nashiruddin Al-Albani, Syaikh Muhammad. Shahih Sunan Tirmidzi Edisi Full CHM

$\begin{array}{lll}\text { Muslim, } & \text { Mukhtashar } & \text { Shahih } \\ \text { 26.03.2009 } & & \end{array}$

Nurkancana, Wayan dan Sumartana. 1986. Evaluasi Pendidikan. Surabaya : Usaha Nasional

Purwanto MP, Drs. M Ngalim. 2000. Psikologi Pendidikan. Bandung : PT Remaja Rosdakarya

Sarwono, Sarlito Wirawan. 2001. Psikologi Sosial Psikologi Kelompok dan psikologi terapan. Jakarta : Balai Pustaka

Sobur, Alex. 2003. Psikologi Umum. Bandung : C Pustaka Setia
Sugiyono. 2015. Metode Penelitian kuantitatif, Kualitatif dan R \& D. Bandung : Alfabeta CV 2015. Metode Penelitian Pendidikan (Pendekatan Kuantitatif, Kualitatif dan R \& D). Bandung : Alfabeta

Sujanto, Agus dkk. 2006. Psikologi Kepribadian. Jakarta : Bumi Aksara

Sumadi Suryabrata. 2008. Psikologi Pendidikan. Jakarta : PT. Raja Grafindo Persada

Suryabrata, Drs. Sumadi. 2012. Psikologi Kepribadian. Jakarta : PT Rajagrafindo Persada

Tasmara, K.H Toto. 2001. Kecerdasan Ruhaniah (Transcendental Intelligence). Jakarta : Gema Insani

Tim Redaksi. 2011. Kamus Bahasa Indonesia untuk Pelajar. Jakarta : Badan Pengembangan dan Pembinaan Bahasa

Turiano, Chapman, Gruenewald, And Mroczek. 2015. Personality and the Leading Behavioral Contributors of Mortality. Jurnal Health Psychology. Vol 3. No 1. $51-60$

Wati, Unik Ambar. 2006. Implementasi Teori Make Belief Play-Vygotsky untuk Perkembangan Moral Siswa. Majalah Ilmiah Pembelajaran nomor 1 , vol 2 
Wilcox, Lynn. 2013. Psikologi Kepribadian Analisis Selukbeluk Kepribadian Manusia. Yogyakarta : IRCiSoD

Wuryandani, Wuri. Peranan Keluarga dalam Menginternalisasikan Nilai Moral Untuk Anak Usia Dini. PPSD FIP UNY

Yusuf LN, Dr. H. Syamsu, M.Pd. 2006. Psikologi Perkembangan Anak dan Remaja. Bandung : PT Remaja Rosdakarya 